\title{
Goal-Directed Fluid Therapy Based on Stroke Volume Variations Improves Fluid Management and Gastrointestinal Perfusion in Patients Undergoing Major Orthopedic Surgery
}

\author{
Ke Peng Jian Li Hao Cheng Fu-hai Ji \\ Department of Anesthesiology, First Affiliated Hospital of Soochow University, Suzhou, China
}

\section{Key Words}

Goal-directed fluid therapy - Stroke volume variation .

FloTrac/Vigileo system · Orthopedic surgery

\begin{abstract}
Objective: To evaluate the influence of stroke volume variation (SVV)-based goal-directed therapy (GDT) on splanchnic organ functions and postoperative complications in orthopedic patients. Subjects and Methods: Eighty patients scheduled for major orthopedic surgery under general anesthesia were randomly allocated to one of two equal groups to receive either intraoperative volume therapy guided by SVV (GDT) or standard fluid management (control). In the SVV group, patients received colloid boluses of $4 \mathrm{ml} / \mathrm{kg}$ to maintain an SVV $<10 \%$ when in the supine position or an SVV $<14 \%$ if prone. In the control group, fluids were given to maintain a mean arterial pressure $>65 \mathrm{~mm} \mathrm{Hg}$, a heart rate $<100 \mathrm{bpm}$, a central venous pressure of 8-14 mm Hg, and a urine output $>0.5 \mathrm{ml} / \mathrm{kg} / \mathrm{h}$. Intraoperative organ perfusion, hemodynamic data, hospitalization, postoperative complications, and mortality were recorded. Results: The heart rate at the end of surgery was significantly lower $(p<0.05)$, there were fewer hypotensive episodes $(p<0.05)$, the arterial and gastric intramucosal $\mathrm{pH}$ were higher $(\mathrm{p}<0.05$ for both), the gastric intramucosal $\mathrm{PCO}_{2}$ was lower $(p<0.05)$, the intraop-
\end{abstract}

\begin{tabular}{|c|c|}
\hline KARGER & $\begin{array}{l}\text { (c) } 2014 \text { S. Karger AG, Basel } \\
1011-7571 / 14 / 0235-0413 \$ 39.50 / 0\end{array}$ \\
\hline $\begin{array}{l}\text { E-Mail karger@karger.com } \\
\text { www.karger.com/mpp }\end{array}$ & $\begin{array}{l}\text { This is an Open Access article licensed under the terms of the } \\
\text { Creative Commons Attribution-NonCommercial 3.0 Un- } \\
\text { ported license (CC BY-NC) (www.karger.com/OA-license), } \\
\text { applicable to the online version of the article only. Distribu- } \\
\text { tion permitted for non-commercial purposes only. }\end{array}$ \\
\hline
\end{tabular}

erative infused colloids and the total infused volume were lower ( $p<0.05$ for both), and the postoperative time to flatus was shorter $(p<0.05)$ in the GDT group than in the control group. No differences in the length of hospital stay, complications, or mortality were found between the groups. Conclusion: SVV-based GDT during major orthopedic surgery reduced the volume of the required intraoperative infused fluids, maintained intraoperative hemodynamic stability, and improved the perioperative gastrointestinal function.

ㄷ) 2014 S. Karger AG, Basel

\section{Introduction}

Fluid balance is a major contributing factor to postoperative morbidity and mortality. Persistent hypovolemia is associated with organ hypoperfusion, systemic inflammatory response syndrome, sepsis, and multiple organ failure. Fluid overload, on the other hand, is associated with edema, ileus, postoperative nausea and vomiting, pulmonary complications, and increased cardiac demands [1]. Traditional methods to monitor the preload are based on measurements of pressure or volume, such

Trial registration: ChiCTR-TRC-12002701. 
as the mean arterial pressure (MAP), the heart rate, or the central venous pressure (CVP). However, these are static parameters and do not accurately reflect fluid responsiveness [2]. The individualized 'goal-directed therapy' (GDT) concept [3-5] is a more rational strategy for perioperative fluid therapy, which achieves the maximal cardiac stroke volume via targeted administration of i.v. fluids, blood, and/or vasoactive substances. The FloTrac/ Vigileo system provides automatic and continuous monitoring of the cardiac output, stroke volume, and stroke volume variation (SVV) based on arterial pulse contour analysis. According to our previous study [6] and data from similar studies [7-9], SVV is a sensitive predictor of fluid responsiveness.

Fluid management is a crucial issue for patients undergoing major orthopedic surgery, in which large blood loss, transfusions, fluid shifts, and high incidences of postoperative complications are important concerns. Herein, we report the results of a prospective, randomized, controlled study that compared the intraoperative laboratory parameters of organ functions and postoperative complications between standard care management and SVV-based goaldirected fluid therapy. The primary study endpoint was gastrointestinal function, including the gastric intramucosal partial pressure of carbon dioxide $\left(\mathrm{P}_{\mathrm{g}} \mathrm{CO}_{2}\right)$, the gastric intramucosal $\mathrm{pH}\left(\mathrm{pH}_{\mathrm{i}}\right)$, and the time to passing the first flatus. We hypothesized that the use of goal-directed volume therapy would result in better gastrointestinal perfusion and fewer postoperative complications in patients undergoing major orthopedic surgery.

\section{Subjects and Methods}

\section{Subjects}

The Institutional Research Ethics Committee approved this trial and written informed consent was obtained from all patients. Patients scheduled for elective major orthopedic surgery, including total hip arthroplasty, spinal fusion surgery, femoral fracture surgery, and sacral tumor surgery under general anesthesia, with an anticipated blood loss $>800 \mathrm{ml}$, were eligible for inclusion into this study. Patients were excluded if they were under 18 years old or had a BMI $>40$ or $<15$, coagulopathy, significant arrhythmia or cardiopulmonary dysfunction, or significant renal or liver diseases.

Eighty patients were randomized preoperatively into either a standard care management group (control, $\mathrm{n}=40$ ) or a goal-directed fluid therapy group (GDT, $\mathrm{n}=40$ ) using a random number generator in sealed envelopes. The anesthetist (K.P.) responsible for intraoperative management was aware of the group assignment, whereas all other members of the research team, other health care providers, and the patients were not.
Anesthesia and Monitoring

All patients fasted for $6 \mathrm{~h}$ before surgery and were premedicated with i.v. midazolam $(0.01 \mathrm{mg} / \mathrm{kg})$. A central venous catheter was inserted via the right internal jugular vein and an arterial line was inserted into the radial artery of the nondominant forearm. Standard monitoring included an ECG, MAP, CVP, pulse oximetry, temperature, end-tidal carbon dioxide, and the bispectral index.

In both groups, standard general anesthesia was induced with i.v. fentanyl (3-4 $\mu \mathrm{g} / \mathrm{kg})$, propofol (1.5-2 $\mathrm{mg} / \mathrm{kg})$, and vecuronium $(0.15 \mathrm{mg} / \mathrm{kg})$. After tracheal intubation, the lungs were ventilated at $8 \mathrm{ml} / \mathrm{kg}$ of tidal volume in a volume-controlled mode with $0-3$ $\mathrm{mm} \mathrm{Hg}$ positive end-expiratory pressure. The respiratory rate was set to maintain the end-tidal carbon dioxide at $35-40 \mathrm{~mm} \mathrm{Hg}$. The ventilator settings were unchanged during this study. Anesthesia was maintained with sevoflurane $2-3 \%$ in oxygen and fentanyl adjusted to maintain a bispectral index of 45-55. The body temperature was maintained at $>36^{\circ} \mathrm{C}$ by a fluid warmer. A tonometry tube was inserted into the lumen of the stomach via the nasogastric route and was connected to a $\mathrm{CO}_{2}$ monitor (Tonocap).

After induction of anesthesia, patients scheduled for spinal or sacral surgery were placed in the prone position on a prone pad with 4 small pads ( 2 shoulder and 2 pelvic supports) to allow the chest and abdomen to hang free. All of the patients received an i.v. prophylactic antibiotic and preemptive analgesia of $50 \mathrm{mg}$ flurbiprofen axetil before skin incision. All operations were performed by the same surgical team.

\section{Study Protocol}

The intraoperative fluid management is shown in figure 1. In both groups, intraoperative basal fluid replacement was achieved by continuous infusion of $5 \mathrm{ml} / \mathrm{kg} / \mathrm{h}$ crystalloid solution (Ringer's acetate). In the GDT group, an additional bolus of $4 \mathrm{ml} / \mathrm{kg}$ colloid solution (Voluven 130/0.4; 6\%) was given when the SVV (measured by the FloTrac/Vigileo 3.0) increased $>10 \%$ in the supine position or $>14 \%$ in the prone position. Fluid boluses were repeated every $5 \mathrm{~min}$ if the criteria were met. In the control group, the anesthesiologist (K.P.) was free to give additional fluids, based on the subject's hemodynamic condition and responses, to maintain an MAP $>65 \mathrm{~mm} \mathrm{Hg}$, a heart rate $<100 \mathrm{bpm}$, a CVP of 8-14 mm $\mathrm{Hg}$, and a urine output $>0.5 \mathrm{ml} / \mathrm{kg} / \mathrm{h}$.

In both groups, anemia (hemoglobin level $<80$ g/l or hematocrit $<28 \%$ ) and an acute blood loss $>20 \%$ of the calculated patient circulatory volume were corrected with transfusions of packed red blood cells and fresh frozen plasma in ratios approaching 2:1. Ephedrine boluses of $10 \mathrm{mg}$ or phenylephrine boluses of $50 \mu \mathrm{g}$ were given when fluid boluses failed to maintain a systolic arterial pressure $>90 \mathrm{~mm} \mathrm{Hg}$ or an MAP >65 mm Hg. These episodes were recorded as hypotensive events.

Arterial blood samples were taken at the time of skin incision and closure for blood counts, acid-base balance analysis, and other biochemical laboratory tests. At the same time, the $\mathrm{P}_{\mathrm{g}} \mathrm{CO}_{2}$ was recorded. The mucosal-arterial $\mathrm{PCO}_{2}$ gap was calculated as:

$$
\mathrm{P}_{\mathrm{g}-\mathrm{a}} \mathrm{CO}_{2} \text { gap }=\mathrm{P}_{\mathrm{g}} \mathrm{CO}_{2}-\mathrm{P}_{\mathrm{a}} \mathrm{CO}_{2},
$$

where $\mathrm{P}_{\mathrm{a}} \mathrm{CO}_{2}$ is the arterial carbon dioxide tension.

In addition, the $\mathrm{pH}_{\mathrm{i}}$ was calculated [10] as:

$$
\mathrm{pH}_{\mathrm{i}}=\operatorname{arterial} \mathrm{pH}+\log _{10}\left(\mathrm{P}_{\mathrm{a}} \mathrm{CO}_{2} / \mathrm{P}_{\mathrm{g}} \mathrm{CO}_{2}\right)
$$




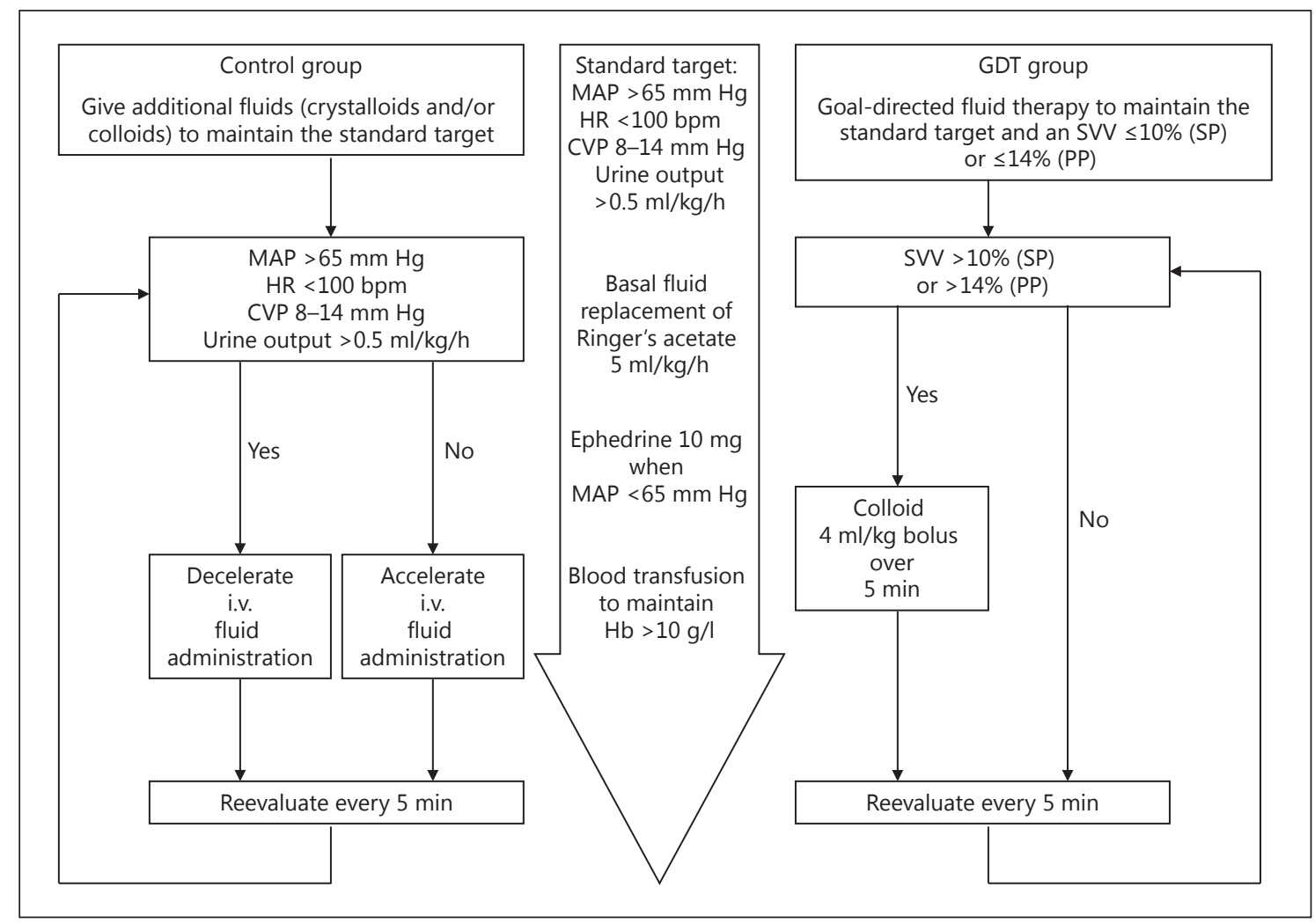

Fig. 1. Intraoperative fluid management. $\mathrm{HR}=\mathrm{Heart}$ rate; $\mathrm{Hb}=$ hemoglobin; $\mathrm{SP}=$ supine position; $\mathrm{PP}=$ prone position.

Patients were transferred to either the intensive care unit or the postanesthesia care unit and were extubated when they fulfilled the standard clinical criteria (oxygenation, hemodynamics, and protective reflexes). Patient-controlled i.v. analgesia with fentanyl (background infusion of $0.4 \mu \mathrm{g} / \mathrm{kg} / \mathrm{h}$, bolus dose of $0.4 \mu \mathrm{g} / \mathrm{kg}$, and lockout interval of $10 \mathrm{~min}$ ) was used during the next 2 postoperative days. Regional anesthesia or analgesia (e.g. epidural catheters or nerve blocks) was not used in this study.

The same surgical team was in charge of the postoperative care, including fluid management (baseline crystalloid infusion of 40 $50 \mathrm{ml} / \mathrm{kg}$ /day, colloids, and transfusions if required), daily antibiotics for 2-3 days, rescue analgesia (100 mg i.v. flurbiprofen axetil or $10 \mathrm{mg}$ i.m. morphine), and antiemetics (10 mg i.v. metoclopramide or $3 \mathrm{mg}$ i.v. granisetron). The discharge criteria were predefined by the Department of Orthopedics at our institution.

Postoperative complications were defined as follows: (a) cardiac complications: hypotension (MAP $<65 \mathrm{~mm} \mathrm{Hg}$ or SAP $<90$ $\mathrm{mm} \mathrm{Hg}$ ), arrhythmias (severe arrhythmias resulting in hemodynamic instability), or heart failure; (b) respiratory complications: ventilator support (need for mechanical ventilation in the intensive care unit), acute lung injury, or acute respiratory distress syndrome $\left(\mathrm{PaO}_{2} / \mathrm{FiO}_{2}<300 \mathrm{~mm} \mathrm{Hg}\right)$; (c) abdominal complications: gastrointestinal hemorrhage (hematemesis and melena), hepatic dysfunction (transaminase >double the upper limit of normal), or hepatic failure (progressive jaundice rise and hepatic encephalopathy); (d) renal complications: renal dysfunction (creatinine $>180$ $\mu \mathrm{mol} / \mathrm{l}$ ) or renal failure (creatinine $>450 \mu \mathrm{mol} / \mathrm{l}$ ); (e) cerebral complications: postoperative cognitive dysfunction or coma; (f) infectious complications: wound infection or wound dehiscence, and (g) others: deep vein thrombosis, nausea, or vomiting. Postoperative complications, fluid management, drainage, length of hospital stay, and mortality were recorded.

\section{Statistical Analysis}

The statistical power analysis was based on a review of our hospital database, which showed an average time to passing the first flatus of $15.32 \pm 5.16 \mathrm{~h}$. Thirty-six patients per group were required for detection of a $20 \%$ difference in the postoperative first flatus time between the two groups with an a level of significance of 0.05 and a power of $80 \%$ (PASS 11.0.7). To compensate for dropped cases, 40 patients were studied in each group.

The statistical analysis was performed using SPSS 19.0 statistical software (IBM SPSS). Data were checked for normality using the Kolmogorov-Smirnov test. Continuous normally distributed data are presented as means \pm SD and were analyzed using paired or unpaired t tests. Nonnormally distributed data are presented as medians (IQR) and were tested using the Mann-Whitney U test and the Wilcoxon rank-sum test for unpaired and paired results, respectively. Categorical data are presented as numbers (\%) and were compared using Fisher's exact test. $\mathrm{p}<0.05$ was considered statistically significant for all tests. 


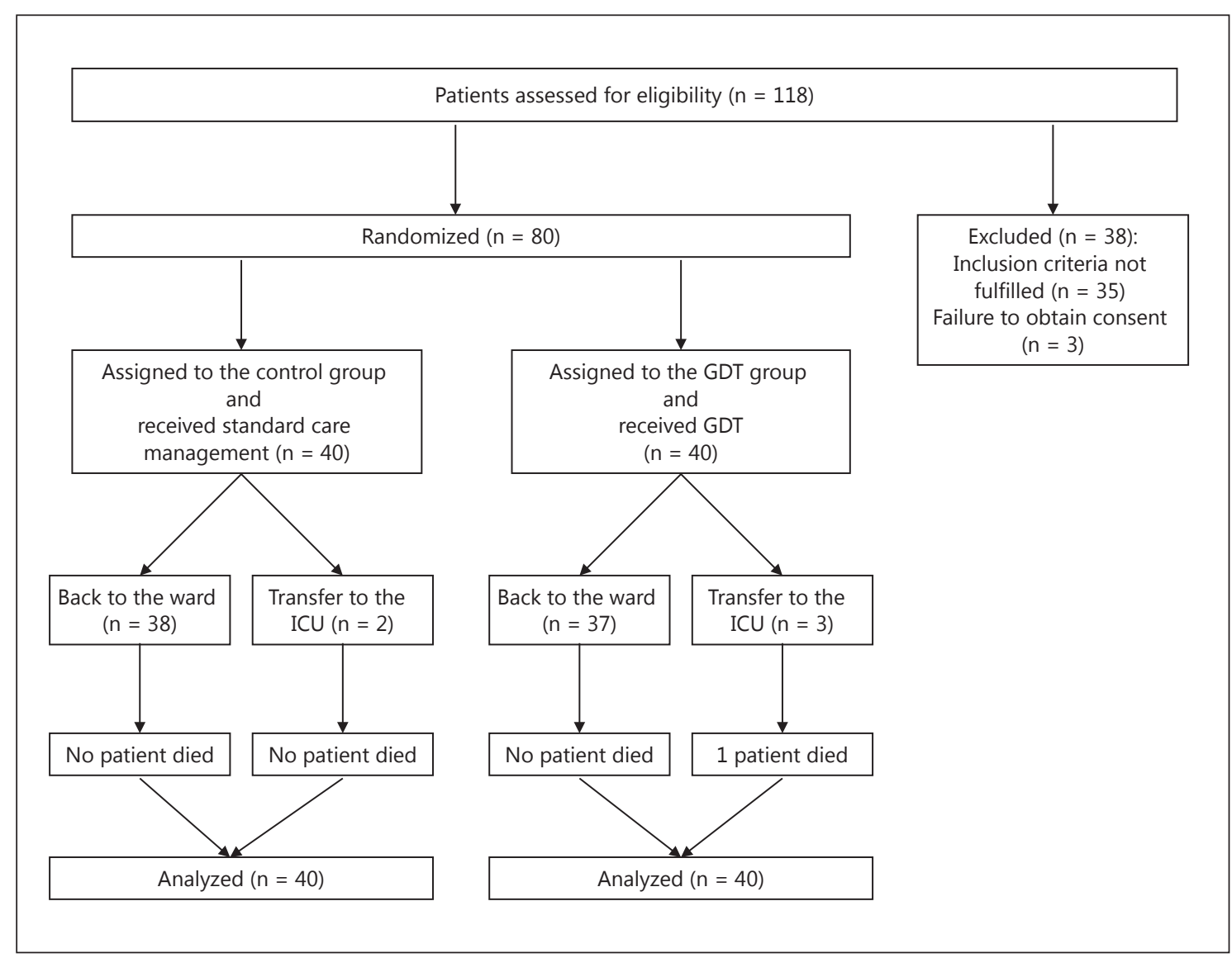

Fig. 2. Flowchart of the patients in this study. ICU = Intensive care unit.

\section{Results}

All 80 patients completed this study. No patient was excluded or dropped out of the study after randomization (fig. 2). There were no significant differences between the groups with regard to demographics and surgical characteristics (table 1).

In both groups, at the end of surgery, the MAP decreased and the CVP increased compared to the baseline values (table 2). Similarly, the mean hemoglobin and hematocrit decreased significantly in both groups $(\mathrm{p}<0.05$ for all). The mean heart rate in the GDT group (68 \pm 13 bpm) was significantly lower than that in the control group (75 $\pm 13 \mathrm{bpm}, \mathrm{p}=0.028)$, and there were fewer hypotensive episodes $(\mathrm{n}=0$, IQR $0-1$, compared to $\mathrm{n}=1$, IQR 0-2, p = 0.021).

Also in the GDT group, at the end of surgery the mean SVV $(7 \pm 1)$ was significantly lower than the mean preoperative value $(9 \pm 2, \mathrm{p}=0.000)$, with a trend to- ward higher cardiac outputs $(4.79 \pm 1.24 \mathrm{l} / \mathrm{min}$ compared to $4.41 \pm 1.07 \mathrm{l} / \mathrm{min}, \mathrm{p}=0.057)$. The SVV and cardiac output were not evaluated in the control group.

The arterial and gastric $\mathrm{pH}_{\mathrm{i}}$ decreased at the end of surgery, while the arterial and gastric intramucosal $\mathrm{CO}_{2}$ tensions, $\mathrm{P}_{\mathrm{g}-\mathrm{a}} \mathrm{CO}_{2}$, and the lactic acid concentration increased. At the end of surgery, compared to the control group, the mean gastric intramucosal $\mathrm{CO}_{2}$ of the GDT group was significantly lower $(48.96 \pm 11.34 \mathrm{~mm} \mathrm{Hg} \mathrm{com-}$ pared to $42.90 \pm 10.01 \mathrm{~mm} \mathrm{Hg}, \mathrm{p}=0.013)$, while the arterial and gastric $\mathrm{pH}_{\mathrm{i}}$ were higher $(7.34 \pm 0.05$ compared to $7.36 \pm 0.06, \mathrm{p}=0.048$, and $7.30 \pm 0.11$ compared to 7.37 $\pm 0.11, \mathrm{p}=0.007$, respectively).

The volume of infused intraoperative colloids was significantly lower in the GDT group than in the control group (500 ml, IQR 312-1,000, compared to $1,000 \mathrm{ml}$, IQR $500-1,000, p=0.003)$. Similarly, the total infused volume in the GDT group was also significantly lower (1,850 ml, IQR 1,525-2,537, compared to 2,225 ml, IQR 
Table 1. Demographic patient data and surgical characteristics

\begin{tabular}{lccc}
\hline & GDT & Control & $\begin{array}{l}\mathrm{p} \\
\text { value }\end{array}$ \\
& & & \\
\hline Gender (male/female), $\mathrm{n}$ & $17 / 23$ & $18 / 22$ & 0.822 \\
Age, years & $55 \pm 13$ & $53 \pm 10$ & 0.505 \\
Weight, kg & $59 \pm 10$ & $62 \pm 11$ & 0.216 \\
Height, cm & $162 \pm 8$ & $164 \pm 9$ & 0.329 \\
BMI & $22.66 \pm 3.22$ & $23.25 \pm 3.24$ & 0.421 \\
Position (supine/prone), $\mathrm{n}$ & $25 / 15$ & $22 / 18$ & 0.496 \\
ASA (I/II/III), n & $17 / 22 / 1$ & $17 / 21 / 2$ & 0.837 \\
Surgery & & & \\
$\quad$ Hip & $21(52.5)$ & $20(50.0)$ & 0.823 \\
$\quad$ Spine & $16(40.0)$ & $18(45.0)$ & 0.651 \\
$\quad$ Femur & $2(5.0)$ & $1(2.5)$ & 1.000 \\
$\quad$ Sacrum & $1(2.5)$ & $1(2.5)$ & 1.000 \\
Comorbidity & & & \\
$\quad$ Hypertension & $11(27.5)$ & $15(37.5)$ & 0.340 \\
$\quad$ Diabetes mellitus & $2(5.0)$ & $7(17.5)$ & 0.157 \\
Anemia & $5(12.5)$ & $2(5.0)$ & 0.432 \\
COPD & $2(5.0)$ & $1(2.5)$ & 1.000 \\
Multiple trauma & $3(7.5)$ & $2(5.0)$ & 1.000 \\
Tuberculosis & $2(5.0)$ & $0(0)$ & 0.494 \\
Coronary artery disease & $0(0)$ & $1(2.5)$ & 1.000 \\
Heart block & $2(5.0)$ & $1(2.5)$ & 1.000 \\
Cerebral infarction & $1(2.5)$ & $2(5.0)$ & 1.000 \\
Duration of surgery, min & $175 \pm 100$ & $162 \pm 80$ & 0.520 \\
Intraoperative BIS & $52 \pm 2$ & $53 \pm 2$ & 0.298 \\
\hline & & & \\
\hline
\end{tabular}

Values are presented as means \pm SD or numbers (\%) unless otherwise stated. ASA = American Society of Anesthesiologists physical status classification; $\mathrm{COPD}=$ chronic obstructive pulmonary disease; $\mathrm{BIS}=$ bispectral index.

$1,850-2,900, p=0.036)$. The volume of blood loss, infused crystalloids, infused blood products, and urinary output did not differ between the groups.

The time to the first passage of flatus was significantly shorter in the GDT group (10.82 $\pm 5.83 \mathrm{~h}$ compared to $14.97 \pm 11.17 \mathrm{~h}, \mathrm{p}=0.042$; table 3 ). There was no significant difference between the two groups with regard to the postoperative amount of infused fluids, urine output and drainage volume at $0-24$ or $24-48 \mathrm{~h}$, or the volume of blood transfusion. There were also no differences in postoperative nausea and vomiting, patient-controlled analgesia requests, the number of patients who developed complications, the length of postoperative hospital stay, or mortality. One patient who underwent resection of a sacral tumor in the GDT group died from septic shock 17 days after surgery.

Fluid Management in Major Orthopedic Surgery

\section{Discussion}

The main findings of the present study are that SVVbased GDT during major orthopedic surgery reduced the required volume of intraoperative infused fluids, maintained intraoperative hemodynamic stability, and improved the perioperative gastrointestinal function.

Perioperative fluid management is challenging in high-risk surgical patients. The aim of volume therapy is not only to prevent hypovolemia but also to reduce the risk of fluid overload. Hypovolemia is recognized as a risk factor for adverse effects, ranging from minor organ dysfunction to multiple organ failure and even death. Conversely, fluid overload may impair pulmonary, cardiac, and gastrointestinal functions, contributing to postoperative complications and a prolonged recovery [11]. Therefore, appropriate hemodynamic monitoring is important for intraoperative fluid management. To our knowledge, this study is the first to directly compare conventional intraoperative management with SVV-based goal-directed fluid therapy with regard to organ functions and postoperative complications in patients undergoing major orthopedic surgery.

Ideally, a simple, affordable, and reliable method to improve intraoperative fluid management is desirable for routine use. Esophageal Doppler has been used to guide fluid management, with good results [12], but its use is partially limited by the need for experienced staff [13]. Also, the reliability of this method in major vascular procedures requiring cross-clamping of the descendent aorta has been questioned. On the other hand, arterial cannulation is routinely used in high-risk patients, and application of the FloTrac/Vigileo system is generally well tolerated by patients, without increased invasion and risk.

As reported in our previous study [6], the SVV obtained by the Vigileo/FloTrac system was a more sensitive predictor of fluid responsiveness than MAP, heart rate, or CVP measurements for intravascular volume assessment. Although the optimal cut-off value for SVV remains uncertain, the $10 \%$ threshold suggested by Manecke [14] for patients in the supine position and the $14 \%$ threshold for patients in the prone position [8] were considered to be the best available estimates for the Vigileo/FloTrac system. In our institution, patients scheduled for spinal or sacral surgery were placed in the prone position on a prone pad with 4 small pads ( 2 shoulder and 2 pelvic supports) to allow the chest and abdomen to hang free, which is similar to the method described by Biais et al. [8]. Therefore, we used an SVV of 10\% for patients in the supine position and an SVV of 14\% for patients in the prone 
Table 2. Intraoperative hemodynamic data, laboratory parameters, and fluid management

\begin{tabular}{|c|c|c|c|c|}
\hline & \multicolumn{2}{|l|}{ GDT } & \multicolumn{2}{|l|}{ Control } \\
\hline & baseline & end of surgery & baseline & end of surgery \\
\hline \multicolumn{5}{|l|}{ Hemodynamic data } \\
\hline Heart rate, bpm & $68 \pm 11$ & $68 \pm 13^{\mathrm{a}}$ & $73 \pm 13$ & $75 \pm 13$ \\
\hline MAP, mm Hg & $88 \pm 9$ & $79 \pm 10^{b}$ & $91 \pm 10$ & $81 \pm 12^{b}$ \\
\hline $\mathrm{CVP}, \mathrm{mm} \mathrm{Hg}$ & $8 \pm 3$ & $10 \pm 3^{\mathrm{b}}$ & $8 \pm 3$ & $10 \pm 3^{\mathrm{b}}$ \\
\hline SVV,$\%$ & $9 \pm 2$ & $7 \pm 1^{\mathrm{b}}$ & NA & NA \\
\hline Cardiac output, $1 / \mathrm{min}$ & $4.41 \pm 1.07$ & $4.79 \pm 1.24$ & NA & NA \\
\hline Hypotensive events & $0(0-1)^{\mathrm{a}}$ & & $1(0-2)$ & \\
\hline \multicolumn{5}{|l|}{ Laboratory parameters } \\
\hline $\mathrm{P}_{\mathrm{g}} \mathrm{CO}_{2}, \mathrm{~mm} \mathrm{Hg}$ & $29.29 \pm 5.57$ & $42.90 \pm 10.01^{\mathrm{a}, \mathrm{b}}$ & $30.81 \pm 5.63$ & $48.96 \pm 11.34^{\mathrm{b}}$ \\
\hline $\mathrm{P}_{\mathrm{a}} \mathrm{CO}_{2}, \mathrm{~mm} \mathrm{Hg}$ & $39.10 \pm 6.83$ & $42.11 \pm 9.07^{\mathrm{b}}$ & $40.63 \pm 6.11$ & $44.26 \pm 6.75^{\mathrm{b}}$ \\
\hline $\mathrm{P}_{\mathrm{g}-\mathrm{a}} \mathrm{CO}_{2}, \mathrm{~mm} \mathrm{Hg}$ & $-9.80 \pm 9.44$ & $0.78 \pm 14.48^{\mathrm{b}}$ & $-9.82 \pm 6.76$ & $4.52 \pm 11.48^{\mathrm{b}}$ \\
\hline $\mathrm{pH}_{\mathrm{a}}$ & $7.42 \pm 0.04$ & $7.36 \pm 0.06^{\mathrm{a}, \mathrm{b}}$ & $7.42 \pm 0.05$ & $7.34 \pm 0.05^{\mathrm{b}}$ \\
\hline $\mathrm{pH}_{\mathrm{i}}$ & $7.55 \pm 0.10$ & $7.37 \pm 0.11^{\mathrm{a}, \mathrm{b}}$ & $7.54 \pm 0.08$ & $7.30 \pm 0.11^{\mathrm{b}}$ \\
\hline Lactate, $\mathrm{mmol} / \mathrm{l}$ & $1.54 \pm 0.32$ & $2.12 \pm 0.89^{b}$ & $1.61 \pm 0.57$ & $2.35 \pm 1.02^{\mathrm{b}}$ \\
\hline Hemoglobin, g/l & $12.03 \pm 1.81$ & $10.52 \pm 1.54^{\mathrm{b}}$ & $11.94 \pm 1.69$ & $10.28 \pm 1.61^{\mathrm{b}}$ \\
\hline Hematocrit & $0.37 \pm 0.05$ & $0.33 \pm 0.04^{\mathrm{b}}$ & $0.37 \pm 0.04$ & $0.32 \pm 0.04^{\mathrm{b}}$ \\
\hline \multicolumn{5}{|l|}{ Fluid management } \\
\hline Blood loss, $\mathrm{ml}$ & \multicolumn{2}{|c|}{$800(600-1,000)$} & \multicolumn{2}{|c|}{$800(525-1,200)$} \\
\hline Crystalloids infused, ml & \multicolumn{2}{|c|}{$1,000(712-1,000)$} & \multicolumn{2}{|c|}{$1,000(500-1,000)$} \\
\hline Colloids infused, ml & \multicolumn{2}{|c|}{$500(312-1,000)^{\mathrm{a}}$} & \multicolumn{2}{|c|}{$1,000(500-1,000)$} \\
\hline PRBC infused, $\mathrm{ml}$ & \multicolumn{2}{|c|}{$600(400-600)$} & \multicolumn{2}{|c|}{$600(400-800)$} \\
\hline FFP infused, $\mathrm{ml}$ & \multicolumn{2}{|c|}{$0(0-200)$} & \multicolumn{2}{|c|}{$0(0-200)$} \\
\hline Total volume infused, $\mathrm{ml}$ & \multicolumn{2}{|c|}{$1,850(1,525-2,537)^{\mathrm{a}}$} & \multicolumn{2}{|c|}{$2,225(1,850-2,900)$} \\
\hline Urinary output, ml & \multicolumn{2}{|c|}{$300(200-400)$} & \multicolumn{2}{|c|}{$300(200-475)$} \\
\hline Urinary output, $\mathrm{ml} / \mathrm{kg} / \mathrm{h}$ & \multicolumn{2}{|c|}{$1.98(1.29-2.63)$} & \multicolumn{2}{|c|}{$2.20(1.53-3.25)$} \\
\hline
\end{tabular}

Values are presented as means \pm SD or medians $(I Q R) . N A=$ Not available; $P R B C=$ packed red blood cells; $\mathrm{FFP}=$ fresh frozen plasma; $\mathrm{pH}_{\mathrm{a}}=$ arterial $\mathrm{pH} ; \mathrm{pH}_{\mathrm{i}}=$ intramucosal $\mathrm{pH} ; \mathrm{P}_{\mathrm{g}} \mathrm{CO}_{2}=$ gastric intramucosal partial pressure of carbon dioxide; $\mathrm{P}_{\mathrm{a}} \mathrm{CO}_{2}=$ arterial partial pressure of carbon dioxide; $\mathrm{P}_{\mathrm{g}-\mathrm{a}} \mathrm{CO}_{2}=$ mucosal-arterial $\mathrm{PCO}_{2}$ gap. ${ }^{\mathrm{a}} \mathrm{p}<0.05$ between the two groups. ${ }^{\mathrm{b}} \mathrm{p}<0.05$ in comparison to baseline values.

position as the thresholds for hypovolemia to target volume optimization in our study.

In many studies [15-19], patients who had their fluid requirements managed with a goal-directed protocol received greater amounts of colloids than those who were treated with conventional or restrictive fluid management. Similarly, our results support that the use of intraoperative fluid therapy with accurate targeting of colloid fluid boluses may prevent excessive fluid administration. Greater amounts of infused fluids were less effective and jeopardized gastrointestinal function. In normovolemic healthy volunteers, $16 \%$ of colloids and more than $68 \%$ of the saline solution escaped into the extravascular fluid compartment $1 \mathrm{~h}$ after the infusion [20]. Edema of the intestines and other tissues may be responsible for poor tissue oxygenation and postoperative gut dysfunction [21]. Smaller volumes of infused fluids may help protect the gastrointestinal tract from dysfunction, which may help explain the shorter flatus time in the GDT group.

Regarding the lactate level, it is an indirect but sensitive measure of organ perfusion. Increased lactate correlates with an inadequate intravascular volume, tissue hypoxia, and energy failure due to blood flow redistribution [22]. In the present study, lactate-free fluids were used for volume substitution to exclude a potential bias. Our results showed that patients in both groups suffered a significant increase in lactate levels at the end of surgery relative to baseline values, indicating that these major surgical procedures had a great effect on organ perfusion. Tonometry, on the other hand, is a relatively noninvasive technique that measures the $\mathrm{P}_{\mathrm{g}} \mathrm{CO}_{2}$; from this value, associated parameters such as the $\mathrm{pH}_{\mathrm{i}}$ and the $\mathrm{PCO}_{2}$ gap $\left(\mathrm{P}_{\mathrm{gCO}} \mathrm{CO}_{2}\right.$ $\mathrm{P}_{\mathrm{a}} \mathrm{CO}_{2}$ ) can be calculated. Low $\mathrm{pH}_{\mathrm{i}}$, high $\mathrm{P}_{\mathrm{g}} \mathrm{CO}_{2}$, and high 
Table 3. Postoperative complications and fluid management

\begin{tabular}{|c|c|c|c|}
\hline & GDT & Control & $\mathrm{p}$ value \\
\hline \multicolumn{4}{|l|}{ Cardiovascular complications } \\
\hline Hypotension & $3(7.5)$ & $2(5.0)$ & 0.432 \\
\hline Arrhythmias & $1(2.5)$ & $0(0)$ & 1.000 \\
\hline Heart failure & $0(0)$ & $0(0)$ & 1.000 \\
\hline \multicolumn{4}{|l|}{ Respiratory complications } \\
\hline Ventilator support & $2(5.0)$ & $2(5.0)$ & 1.000 \\
\hline ALI/ARDS & $1(2.5)$ & $0(0)$ & 1.000 \\
\hline \multicolumn{4}{|l|}{ Abdominal complications } \\
\hline Flatus time, $\mathrm{h}$ & $10 \pm 5$ & $14 \pm 11$ & $0.042^{\mathrm{a}}$ \\
\hline Gastrointestinal hemorrhage & $0(0)$ & $0(0)$ & 1.000 \\
\hline Hepatic dysfunction & $5(12.5)$ & $6(15.0)$ & 0.745 \\
\hline Hepatic failure & $1(2.5)$ & $0(0)$ & 1.000 \\
\hline \multicolumn{4}{|l|}{ Renal complications } \\
\hline Urine output $0-24 \mathrm{~h}, \mathrm{ml}$ & $1,625(1,175-2,412)$ & $2,000(1,150-2,700)$ & 0.263 \\
\hline Urine output $24-48 \mathrm{~h}, \mathrm{ml}$ & $2,500(1,800-3,100)$ & $2,200(1,700-3,525)$ & 0.672 \\
\hline Renal dysfunction & $1(2.5)$ & $3(7.5)$ & 0.615 \\
\hline Renal failure & $1(2.5)$ & $0(0)$ & 1.000 \\
\hline \multicolumn{4}{|l|}{ Central nervous complications } \\
\hline POCD & $1(2.5)$ & $1(2.5)$ & 1.000 \\
\hline Coma & $1(2.5)$ & $0(0)$ & 1.000 \\
\hline \multicolumn{4}{|l|}{ Infection-related complications } \\
\hline Pneumonia & $4(10.0)$ & $3(7.5)$ & 1.000 \\
\hline Wound infection & $0(0)$ & $1(2.5)$ & 1.000 \\
\hline Wound dehiscence & $0(0)$ & $0(0)$ & 1.000 \\
\hline Deep vein thrombosis & $0(0)$ & $1(2.5)$ & 1.000 \\
\hline Nausea & $5(12.5)$ & $8(20.0)$ & 0.363 \\
\hline Vomit & $2(5.0)$ & $5(12.5)$ & 0.432 \\
\hline PCA requests & $0(0-2)$ & $0(0-2)$ & 0.719 \\
\hline \multicolumn{4}{|l|}{ Fluid management, drainage } \\
\hline Fluid infused $0-24 \mathrm{~h}, \mathrm{ml}$ & $2,189 \pm 659$ & $2,109 \pm 709$ & 0.606 \\
\hline Fluid infused $24-48 \mathrm{~h}, \mathrm{ml}$ & $1,766 \pm 965$ & $1,806 \pm 944$ & 0.852 \\
\hline Blood transfusion, $\mathrm{ml}$ & $0(0-200)$ & $0(0-200)$ & 0.625 \\
\hline Drainage volume $0-24 \mathrm{~h}, \mathrm{ml}$ & $132(100-263)$ & $107(38-187)$ & 0.062 \\
\hline Drainage volume $24-48 \mathrm{~h}, \mathrm{ml}$ & $60(25-120)$ & $47(16-135)$ & 0.397 \\
\hline Drainage removal time, days & $2 \pm 0$ & $2 \pm 0$ & 0.196 \\
\hline Postoperative stay, days & $12 \pm 3$ & $11 \pm 7$ & 0.802 \\
\hline Mortality & $1(2.5)$ & $0(0)$ & 1.000 \\
\hline
\end{tabular}

Values are presented as numbers (\%), medians (IQR), or means \pm SD. ALI/ARDS $=$ Acute lung injury/acute respiratory distress syndrome; $\mathrm{POCD}=$ postoperative cognitive dysfunction; PCA requests = number of analgesic requirements with patient-control analgesia. ${ }^{a} \mathrm{p}<0.05$ indicates a significant difference.

$\mathrm{PCO}_{2}$ gap values may indicate an inadequate oxygen supply to the bowel, leading to regional acidosis. In addition, intramucosal acidosis has been associated with a poor prognosis and multiple organ failure in critically ill patients, even in the absence of systemic acidosis or hypotension $[23,24]$. Moreover, it has been shown that the correc- tion of intramucosal acidosis may increase the survival rate of critically ill patients [25]. Recently, $\mathrm{P}_{\mathrm{g}} \mathrm{CO}_{2}$ and $\mathrm{pH}_{\mathrm{i}}$ were used as indicators of gastrointestinal function [2628]. In this study, we found that the $\mathrm{P}_{\mathrm{g}} \mathrm{CO}_{2}$ levels were lower and the $\mathrm{pH}_{\mathrm{i}}$ levels were higher at the end of surgery in the GDT group. Similarly, in the GDT group, the post- 
operative flatus time was shorter, indicating better gastrointestinal perfusion compared to the control group.

Our study has some limitations. First, the SVV and $\mathrm{CO}$ values were not available for the control group as the FloTrac/Vigileo device was not attached to these patients. Second, the inclusion of different surgical procedures might have influenced our results, because the pathophysiology and complications vary between joint and spinal surgery. Third, the absence of significant differences between the study groups in the incidence of nausea and vomiting, the length of hospital stay, and the incidence of mortality may have been due to our study not being powered enough to detect differences in these complications.

\section{Conclusion}

In patients undergoing major orthopedic surgery, SVV-based goal-directed intraoperative fluid therapy reduced the volume of intraoperative infused fluids, maintained intraoperative hemodynamic stability, and improved the perioperative gastrointestinal function relative to conventional treatment.

\section{Acknowledgments}

We thank the surgical teams for their technical help and the nurses at the Department of Anesthesiology and Orthopedics for their helpful assistance.

\section{References}

1 Bellamy MC: Wet, dry or something else? Br J Anaesth 2006;97:755-757.

2 Cavallaro F, Sandroni C, Antonelli M: Functional hemodynamic monitoring and dynamic indices of fluid responsiveness. Minerva Anestesiol 2008;74:123-135.

-3 Bundgaard-Nielsen M, Holte K, Secher NH, et al: Monitoring of peri-operative fluid administration by individualized goal-directed therapy. Acta Anaesthesiol Scand 2007;51: 331-340.

-4 Funk DJ, Moretti EW, Gan TJ: Minimally invasive cardiac output monitoring in the perioperative setting. Anesth Analg 2009;108: 887-897.

5 Phan TD, Ismail H, Heriot AG, et al: Improving perioperative outcomes: fluid optimization with the esophageal Doppler monitor, a meta-analysis and review. J Am Coll Surg 2008;207:935-941.

6 Li J, Ji FH, Yang JP: Evaluation of stroke volume variation obtained by the FloTrac/Vigileo system to guide preoperative fluid therapy in patients undergoing brain surgery. J Int Med Res 2012;40:1175-1181.

7 Cannesson M, Musard H, Desebbe O, et al: The ability of stroke volume variations obtained with Vigileo/FloTrac system to monitor fluid responsiveness in mechanically ventilated patients. Anesth Analg 2009;108:513517.

$>8$ Biais M, Bernard O, Ha JC, et al: Abilities of pulse pressure variations and stroke volume variations to predict fluid responsiveness in prone position during scoliosis surgery. $\mathrm{Br} \mathrm{J}$ Anaesth 2010;104:407-413.

9 Zhang Z, Lu B, Sheng X, et al: Accuracy of stroke volume variation in predicting fluid responsiveness: a systematic review and metaanalysis. J Anesth 2011;25:904-916.

10 Huang CC, Tsai YH, Lin MC: Gastric intramucosal $\mathrm{PCO}_{2}$ and $\mathrm{pH}$ variability in venti- lated critically ill patients. Crit Care Med 2001;29:88-95.

11 Bundgaard-Nielsen M, Secher NH, Kehlet $\mathrm{H}$ : 'Liberal' vs. 'restrictive' perioperative fluid therapy-a critical assessment of the evidence. Acta Anaesthesiol Scand 2009;53:843-851.

12 Sinclair S, James S, Singer M: Intraoperative intravascular volume optimisation and length of hospital stay after repair of proximal femoral fracture: randomised controlled trial. BMJ 1997;315:909-912.

13 Lefrant JY, Bruelle P, Aya AG, et al: Training is required to improve the reliability of esophageal Doppler to measure cardiac output in critically ill patients. Intensive Care Med 1998;24:347-352.

14 Manecke GR: Edwards FloTrac sensor and Vigileo monitor: easy, accurate, reliable cardiac output assessment using the arterial pulse wave. Expert Rev Med Devices 2005;2: 523-527.

15 Cecconi M, Fasano N, Langiano N, et al: Goaldirected haemodynamic therapy during elective total hip arthroplasty under regional anaesthesia. Crit Care 2011;15:R132.

16 Mayer J, Boldt J, Mengistu AM, et al: Goaldirected intraoperative therapy based on autocalibrated arterial pressure waveform analysis reduces hospital stay in high-risk surgical patients: a randomized, controlled trial. Crit Care 2010;14:R18.

17 Benes J, Chytra I, Altmann P, et al: Intraoperative fluid optimization using stroke volume variation in high risk surgical patients: results of prospective randomized study. Crit Care 2010;14:R118.

18 Zhang J, Qiao H, He ZY, et al: Intraoperative fluid management in open gastrointestinal surgery: goal-directed versus restrictive. Clinics (Sao Paulo) 2012;67:1149-1155.

19 Scheeren TW, Wiesenack C, Gerlach H, et al: Goal-directed intraoperative fluid therapy guided by stroke volume and its variation in high-risk surgical patients: a prospective randomized multicentre study. J Clin Monit Comput 2013;27:225-233.

20 McIlroy DR, Kharasch ED: Acute intravascular volume expansion with rapidly administered crystalloid or colloid in the setting of moderate hypovolemia. Anesth Analg 2003; 96:1572-1577.

21 Mythen M, Vercueil A: Fluid balance. Vox Sang 2004;87(suppl 1):77-81.

22 Valenza F, Aletti G, Fossali T, et al: Lactate as a marker of energy failure in critically ill patients: hypothesis. Crit Care 2005;9:588593.

23 Nordin A, Makisalo H, Mildh L: Gut intramucosal $\mathrm{pH}$ as an early indicator of effectiveness of therapy for hemorrhagic shock. Crit Care Med 1998;26:1110-1117.

24 Miller PR, Kincaid EH, Meredith JW: Threshold values of intramucosal $\mathrm{pH}$ and mucosalarterial $\mathrm{CO}_{2}$ gap during shock resuscitation. J Trauma 1998;45:868-872.

25 Gutierrez G, Palizas F, Doglio G, et al: Gastric intramucosal $\mathrm{pH}$ as therapeutic index of tissue oxygenation in critically ill patients. Lancet 1992;339:195-199.

26 Wang G, Liu S, Liu G: Effects of infusion of different fluids during controlled hypotension on gastric intramucosal $\mathrm{pH}$ and postoperative gastroenterological function. J Biomed Res 2011;25:191-196.

27 Arya N, Sharif MA, Lau LL, et al: Retroperitoneal approach to abdominal aortic aneurysm repair preserves splanchnic perfusion as measured by gastric tonometry. Ann Vasc Surg 2010;24:321-327.

28 van Haren FM, Pickkers P, Foudraine N, et al: The effects of methylene blue infusion on gastric tonometry and intestinal fatty acid binding protein levels in septic shock patients. J Crit Care 2010;25:358.e1-358.e7. 